\section{Conjuntivites e perda de visão: pediatras estariam na primeira linha de prevenção do ceratocone}

Arq Asma Alerg Imunol. 2021;5(3):312-3.
http://dx.doi.org/10.5935/2526-5393.20210050

Prezado Editor,

O ceratocone (CC) é uma doença ectásica da córnea, progressiva, bilateral, tomando uma forma cônica. Alterações nas fibras de colágeno resultam em um progressivo aumento de sua curvatura e no seu afinamento, com perda de visão. Comparando com adultos, o $\mathrm{CC}$ em crianças progride mais rapidamente, sendo usualmente mais severo no momento do diagnóstico. Portanto, sendo mais precoce, é importante avaliar sua progressão e manter a visão"

Em contraste com o CC em adultos, o CC pediátrico tende a apresentar-se na adolescência, quando é prevalente, mais agressivo, podendo progredir para a segunda ou terceira década da vida, podendo estabilizar-se em alguns $\operatorname{casos}^{2,3}$.

Pode existir uma história familiar positiva para CC por uma característica genética; outrossim uma associação com síndrome de alergia sistêmica, atopia e conjuntivite alérgica, associada a um significante prurido ocular, pode levar a uma rápida progressão e deterioração da visão. $O$ paciente poderá queixar-se de visão embaçada, principalmente à noite, que melhora com o fechamento parcial de ambos os olhos, de fotofobia, de imagens distorcidas e perda de visão ${ }^{3}$.

Pode ser observada uma frequente troca de óculos de grau ou lentes de contato, para corrigir a miopia e/ ou o astigmatismo. Existe uma primeira deformidade da córnea, apresentando um elevado risco de morbidade por CC, particularmente na presença de doenças alérgicas do olho. Deve ser avaliada e intensivamente tratada, especialmente quando existir uma indicação para procedimento invasivo, como crosslinking (colocação de colírio de riboflavina no olho associado a irradiação de raios UVA, para enrijecimento da córnea) ${ }^{1}$.
Justifica-se, nessas especiais circunstâncias, que uma avaliação e um tratamento especializados, associados a um alergista, estariam plenamente indicados.

A deficiência visual em pacientes pediátricos pode afetar o desenvolvimento social e educacional. Inicialmente o CC é unilateral, entretanto a maioria desenvolve a doença de forma bilateral ${ }^{4}$.

Muitas vezes, o CC é uma doença isolada; portanto, o ato de esfregar os olhos aumenta o nível de metaloproteína-13, IL-6 e TNF- $\alpha$, mesmo em olhos normais e nas formas subclínicas, cuja liberação de mediadores inflamatórios contribui para seu desenvolvimento².

As opções não cirúrgicas para o tratamento, para corrigir a miopia e o astigmatismo no CC, podem consistir no uso de óculos de grau ou de lentes de contato, sendo, em crianças, nem sempre toleradas e, muitas vezes, insuficientes para obter uma acuidade visual satisfatória ${ }^{5}$.

Estudos sobre CC pediátrico sugerem que, no tempo do diagnóstico, $27,8 \%$ estão em estado avançado, e $88 \%$, em progressão ${ }^{1}$. Admite-se que procedimentos invasivos realizados por oftalmologistas, como o crosslinking, para aumentar a resistência do colágeno e a estabilização da córnea, são aceitáveis, entretanto a eficácia desse pode não ser efetiva quando comparada com adultos ${ }^{1,2}$.

A prevalência do $\mathrm{CC}$, na população geral, varia de 1:375 a 1:2.000, enquanto na pediátrica está estimado entre 1:200 e 1:25, mais recentemente, como ocorre na Arábia Saudita1.

Pesquisando-se, não há dados em nosso país sobre a incidência ou prevalência do CC. Tal conhecimento poderá determinar estratégias para programas de saúde pública e seu impacto em nosso meio.

A determinação da IgE sérica total e as específicas para alérgenos inaláveis, estão incluídas no rol de procedimentos na prática clínica de pediatras. Estes possuem, desde sua formação, experiência no diagnóstico precoce e no tratamento de doenças alérgicas, entre as quais a rinite, a asma brônquica e a dermatite atópica.

Pacientes com rinoconjuntivite alérgica são avaliados por pediatras, quando é investigada a sensibilização por alérgenos, tratamento da rinite, profilaxia ambiental, se- 
gundo história clínica, e a determinação de IgE específica com o consequente controle da conjuntivite na maioria das vezes.

A biodisponibilidade sistêmica de corticosteroides de segunda geração por via nasal, usados nas doses recomendadas, tais como mometasona e fluticasona, é inferior a $1 \%$, são geralmente seguros e não estão associados a significantes ou irreversíveis efeitos secundários, mesmo por tempo prolongado.

Não existe, na especialidade pediátrica, uma excessiva precaução quando indicado o uso de corticosteroides nasais em crianças diminuindo os sintomas na existência de conjuntivite, através de inibição de reflexo naso-ocular, diferindo, muitas vezes, de cuidadores da saúde ocular, ocupando-se, basicamente, de medicações tópicas oculares.

Estima-se, portanto, que há uma profilaxia precoce e possível para um CC ainda não determinado, principalmente na existência de prurido intenso nos olhos, associado ao ato de coçar, antes mesmo de ser avaliado por oftalmologistas. Outrossim, pediatras estão plenamente habilitados a avaliar a eficácia da imunoterapia específica com alérgenos, induzindo a uma tolerância imunológica, à redução dos sintomas oculares e ao uso de medicações tópicas.

No caso de doenças com ectasia de córnea, coçar os olhos é um "hábito terrível". "É difícil de transmitir mensagens para um impacto em seguida, porque, obviamente, as consequências não são imediatas, sendo que o repetido trauma de córnea pode desenvolver ectasia e também acelerar sua progressão". Essas afirmações são preconizadas pelo Violet June, uma campanha internacional de informações e educação visando à prevenção do CC, estabelecidas por oftalmologistas ${ }^{6}$.

Existem 235 municípios no Brasil com mais de 40 mil habitantes sem atendimento regular de oftalmologistas. Isso também ocorre em 68 deles com mais de 70 mil habitantes, estimando-se que $85 \%$ destes municípios sofrem com a falta de oftalmologistas (fonte: Censo Oftalmológico 2014 - Conselho Brasileiro de Oftalmologia).
No Brasil, uma pesquisa demográfica relativa à distribuição de especialistas titulados enumera, como de Pediatria, 39.234 (10,3\%); de Oftalmologia, 13.825 (3,6\%); e de Alergia/Imunologia 1.601(0,4\%) (fonte: Demografia Médica no Brasil, 2018).

Tomando-se todos os dados em conjunto, pode-se inferir a importância especialmente de pediatras, em uma linha avançada, na prevenção do CC, na perda de visão, em procedimentos cirúrgicos invasivos, na cegueira, associada a uma possível e previsível diminuição dos transplantes de córnea, que, infelizmente, ocupa o primeiro lugar no Brasil.

\section{Referências}

1. Olivo-Paine A, Abdala-Figuerola A, Hernandes-Bogantes E, PedroAguilar L, Chan E, Godefrooij D. Optimal management of pediatric keratoconus: challenges and solutions. Clinical Ophtalmology. 2019;13:1.183-91.

2. Ahuja P, Dadachanji Z, Shetty R, Nagarajan SA, Khamar P, Sethu $S$, et al. Relevance of IgE, allergy and eye rubbing in the pathogenesis and management of Keratoconus. Indian J Ophalmol. 2020;68:2067-74.

3. Anitha V, Vanathi M, Ragavan A, Rajaman R, Ravidran M, Tandon R. Pediatric keratoconus-Current perspectives and clinical challenges. Indian J Ophtalmol. 2021;69(2):214-25.

4. Mukhtar S, Ambati BK. Pediatric keratoconus: a review of the literature. Int Ophthalmol. 2018 Oct;38(5):2257-66.

5. Rathi VM, Mandathara PS, Vaddavalli PK, Srikanth D, Sangwan VS. Fluid filled scleral contact lens in pediatric patients: challenges and outcome. Cont Lens Anterior Eye. 2012;35(4);189-92.

6. Ambrosio Jr R. Violet June: The Global Keratoconus Awareness Campaign. Ophthalmol Ther. 2020;9:685-88.

Não foram declarados conflitos de interesse associados à publicação desta carta.

\section{Francisco Machado Vieira}

Departamento Cientifico de Alergia Ocular da ASBAI Clínica de Alergia e Imunologia, Caxias do Sul -

Caxias do Sul, RS, Brasil. 